\title{
Correlation of cancer antigen 15-3 (CA15-3) serum level and bony metastases in breast cancer patients
}

\author{
Ashraf Fakhari ${ }^{1,2}$, Esmaeil Gharepapagh*1,2 ${ }^{2}$ Shahram Dabiri ${ }^{1,2}$, Neda Gilani ${ }^{3}$ \\ Received: 4 Feb 2019 \\ Published: 19 Dec 2019
}

\section{Abstract}

Background: Cancer antigen 15-3 (CA15-3) is a common tumor marker and the serum level of this tumor marker is evaluated during the treatment period (periodically) in breast cancer patients. Assuming that the elevated serum levels of this tumor marker can be a potential risk, this study was conducted to determine the association between CA15-3 and bone metastasis and CA15-3 and metastasis spreading rate in breast cancer patients.

Methods: In this study, 70 women with the mean of age 51.69 (10.77) years who suffered from breast cancer were studied by performing both bone scintigraphy and measuring CA15-3. Independent sample t test, Fisher's exact test, Spearman rho correlation, and logistic regression were used for inferential section. To determine the new cross section, Roc curve and coordinates of the curve were applied. Also, significance level was set at $\mathrm{p}<0.05$. Data were analyzed by SPSS 16 software.

Results: There was no difference among patients in age $(\mathrm{p}=0.123)$. Assuming the CA15-3 $(\geq 30 \mathrm{U} / \mathrm{mL})$ as a potential risk, there was no association between CA15-3 and bone metastases $(\mathrm{p}=0.167)$. Based on Spearman's rank correlation coefficient, there was no significant correlation between CA15-3 and metastasis spreading rate $(\mathrm{r}=-0.07, \mathrm{p}=0.851)$. Based on ROC curve and Youden's J statistic index, the new cutoff was pointed at CA15-3 $\geq 21.76 \mathrm{Unit} / \mathrm{mL}$, which correlated with bone metastases $(\mathrm{p}<0.001)$.

Conclusion: This study found a decreased cutoff point at CA15-3 ( $\geq 21.76)$ against 30 (routine value). Based on CA15-3 ( $\geq 21.76$ ), there was a correlation between bone metastases and CA15-3, indicating that patients with CA15-3 ( $\geq 21.76)$ were most likely to experience bone metastases.

Keywords: Breast cancer, Bone scintigraphy, CA15-3, Bone metastases

Conflicts of Interest: None declared

Funding: Medical Radiation Sciences Research Team and Tabriz University of Medical Sciences

*This work has been published under CC BY-NC-SA 1.0 license.

Copyright $\odot$ Iran University of Medical Sciences

Cite this article as: Fakhari A, Gharepapagh E, Dabiri Sh, Gilani N. Correlation of cancer antigen 15-3 (CA15-3) serum level and bony metastases in breast cancer patients. Med J Islam Repub Iran. 2019 (19 Dec);33:142. https://doi.org/10.47176/mjiri.33.142

\section{Introduction}

Breast cancer is the most common malignancy in women worldwide (One every 9 women is statistically involved.). About $13 \%$ of American women are afflicted with breast cancer, with the mortality rate of $3 \%(1)$. Despite the in-

Corresponding author: Dr Esmaeil Gharepapagh, gharepapaghe@tbzmed.ac.ir

1. Medical Radiation Sciences Research Team, Tabriz University of Medical Sciences, Tabriz, Iran

2. Department of Radiology, Medical School, Tabriz University of Medical Sciences, Tabriz, Iran

3. Department of Statistics and Epidemiology, Faculty of Health, Tabriz University of Medical Sciences, Tabriz, Iran creased prevalence of breast cancer, statistics show a descending mortality pattern due to screening and treatment developments in the last 2 decades (2). Invasive ductal carcinoma is the most common type of breast malignancy

\section{$\uparrow$ What is "already known” in this topic:}

Tumor marker CA15-3 is considered as an important concern in realm of breast cancer oncology. Generally, CA15-3 serum level $\geq 30$ ([CA15-3] $\geq 30$ ) is deemed as a risk. Due to ascending statistics on breast cancer, it seems that the high-risk threshold of CA15-3 should be deeply taken under consideration.

\section{$\rightarrow$ What this article adds:}

In this study, the relationship between CA15-3 and bone metastases was investigated in patients with breast cancer, and it was suggested that patients with CA15-3 $\geq 21.76 \mathrm{U} / \mathrm{mL}$ are at risk of bone metastases compared to those with CA15-3 ( $\geq 30$ $\mathrm{U} / \mathrm{mL})$. 
which includes $75 \%$ of all cancerous cases. The rate of lymphatic metastasis is considerable in this type of tumor (3). Spreading of initial breast tumor by lymphatic or blood vessels would lead to distant metastasis, especially bone metastases $(73 \%$ in general) that associates with pain, motion problems, neurogenic disorders, hypercalcemia, and pathologic fractures (4-7). Usually, the more delayed the diagnosis, the more probability of metastasis, including brain, bone marrow, liver, lymph nodes, and lungs metastases) (7). The structure of skeletal system is more attractive to metastasis homing because of hematopoietic activity due to high perfusion and growth factors (8). Generally, lymphatic system plays an important role in distribution of malignant cells, but the tumor marker is helpful in determining the extent of the spread of breast cancer, especially spinal metastases $(9,10)$. The bone scintigraphy by ${ }^{99 \mathrm{~m}} \mathrm{Tc}$-bisphosphonates is a well-known method to diagnose bone metastasis (11). To avoid false positive results, a comprehensive patient's history should be taken $(12,13)$. The CA15-3 tumor marker has been widely considered for the prognosis of bone metastases in patients with breast cancer. CA15-3, a high molecular weight glycoprotein $(300-450 \mathrm{kDa})$, is synthesized by apical surface of epithelial ducts and acinic breast cells and is then secreted in milk normally. In cancerous statue, CA15-3 drains into the blood perfusion because of disrupted breast morphology (14). CA15-3 may be helpful in determining the extent of the spread of breast cancer. A high CA15-3 would be a symptom of metastasis, especially bone metastases. It seems that CA15-3 could be considered as a useful factor in prognosis of bone metastases in related patients (5). Based on bone scintigraphy, patients with breast cancer in stages 1,2 , and 3 will statistically be involved with bone metastasis of $2 \%, 10 \%$, and $20 \%$, respectively (5). In this study, a survey was developed on CA15-3 in patients with breast cancer to find a correlation between serum level of CA15-3 and bone metastases by either measuring CA15-3 or bone scintigraphy in the same patient.

In this study, the followings were done: (1) measuring CA15-3; (2) performing bone scintigraphy; (3) studying the correlation of CA15-3 and results of bone scintigraphy; (4) studying the correlation of CA15-3 with bone metastases spreading rate in patients suffering from certain metastases; (5) surveying CA15-3 in patients with no metastatic lesions; and (6) measuring CA15-3 in patients with certain bone metastases. The aim of this study was to investigate whether CA15-3 could be used in the prognosis of bone metastases as an available, more economical, and easy to perform method.

\section{Methods}

In this study, 70 patients with breast cancer were studied by bone scintigraphy. In all patients, the serum level of
CA15-3 tumor marker ([CA15-3]) had previously been measured using chemiluminescence method (ECLIA). Because both procedures (bone scan \& serum test) had been requested by related physicians (oncologists) with long treatment, there was no need to obtain the contest of patients. Moreover, patients were notified that their documents were used in this study surreptitiously. Bone scintigraphy is an objective diagnostic method just for visualization of bony metastases. Routinely, whole body bone scintigraphy was performed by ${ }^{99 m}$ Tc-MDP through dual head gamma camera. The evacuated MDP kits (methylene diphosphonate) were purchased from Pars Isotope Co. and bone scintigraphy was performed by Siemens SPECT dual head gamma camera and low energy-high resolution collimator. The results of scintigraphy were interpreted by $2 \mathrm{nu}-$ clear medicine physicians who were blind to CA15-3. The results from both bone scan and CA15-3 was extracted from patients' documents to find whether there was a correlation between the serum level of CA15-3 and bone metastasis.

Inclusion criteria were as follow: (1) being female; (2) all patients were pathologically confirmed to have breast cancer; (3) all patients suffered only from breast cancer; and (4) CA15-3 was measured in all patients.

Exclusion criteria were as follow: (1) patients with more than one malignancy; (2) patients who underwent chemo/radiotherapy prior to the study; (3) patients with confusing documents.

For the descriptive section, data were presented as mean (SD) for qualitative variables and frequencies (percent) for qualitative variables. Independent sample t test, Fisher's exact test, Spearman rho correlation, and logistic regression with Hosmer-Lemeshow test were used for inferential section. To determine the new cross section, Roc curve and coordinates of the curve were used. $P$ values less than 0.05 $(p<0.05)$ was considered as significant. Data were analyzed by SPSS 16 (SPSS Inc., Chicago, IL) software.

\section{Results}

The patients were classified into 2 groups: (1) 22 patients with no bone metastasis $(\mathrm{N})$; (2) 48 patients with bone metastasis (Y). Both groups were assayed based on age, CA15-3, metastases spreading rate, and CA15-3 $\geq 30$ $\mathrm{U} / \mathrm{mL}$. Moreover, the cutoff point for CA15-3 was routinely considered at $\geq 30$, which is available in https:// emedicine.medscape.com/article/2087491-overview.

Also, the mean number of metastases sites was 2.96 (1.81), with minimum of 1 and maximum of 7 . The mean age of the 2 groups are presented in Table 1. Based on independent sample $t$ test, there was no difference between the 2 groups in age $(\mathrm{p}=0.123)$.

Considering the cutoff point at $\geq 30,8.6 \%$ of all patients experienced bony metastases (abnormal) and the rest were

Table 1. Descriptive statistics for age (years) of patients in the 2 groups

\begin{tabular}{lcccc}
\hline Group & Number $^{*}$ & Mean (SD) & Min-Max & $\mathrm{p}^{*}$ \\
\hline (N) & 22 & $48.73(8.87)$ & $34-67$ & 0.123 \\
(Y) & 48 & $53.04(11.45)$ & $35-81$ & \\
All patients & 70 & $51.69(10.77)$ & $34-81$ & \\
\hline * Based on independent sample t test & & &
\end{tabular}

\footnotetext{
* Based on independent sample t test
} 
normal (without bony metastases). Also, $6 \%$ of group $\mathrm{Y}$ were abnormal and $42 \%$ were normal; and all patients $(100 \%)$ in group $\mathrm{N}$ were normal (Table 2, Diagram 1).

Distribution of patients with/without bony metastases based on CA15-3 is demonstrated in Graph 1. The area under the curve (AUC) for patients with bony metastases was clearly more than that of patients without bony metastases, but more patients had less than CA15-3 $\geq 30 \mathrm{U} / \mathrm{mL}$. According to $(p=0.167)$ and Graph 1 , serum levels above 30 (for tumor markers) are not considered as appropriate risk factors.

There were no statistically significant differences between the 2 groups at cutoff point $\geq 30$ based on the results of Fisher's exact and t test, indicating that there was no considerable association between CA15-3 and bone metastases $(\mathrm{p}=0.167)$.

Based on Spearman's rank correlation coefficient, there was a weak and inverse correlation between CA15-3 and metastasis spreading rate $(\mathrm{r}=-0.07, \mathrm{p}=0.851)$ (Graph 2).

Introducing a new cutoff could cover the possibility of bone metastasis in patients with breast cancer, which was determined at 21.76 based on Table 3 (coordinates of the curve), with sensitivity of 91.70 and specificity of 91.90 , based on ROC curve (Graph 3) and Youden's J statistic index.

The average of CA15-3 for groups N-new and P-new was calculated to be 18.94 (2.01) and 27.05 (4.33), respectively, which should be descripted in abbreviation of N/P-new, the word "new" was used for each group after applying a new cutoff point. Independent sample t test results have shown a significant difference between the 2 groups $(p<0.001)$ (Table 4, Diagram 2). According to $\mathrm{p}>0.05$ for HosmerLemeshow test, logistic regression adjusted for age showed that odds of CA15-3 $\geq 21.76$ in group $\mathrm{Y}$ was obviously more than in group $\mathrm{N}(\mathrm{OR}=11.0, \mathrm{p}<0.001)$.

\begin{tabular}{lccc}
\multicolumn{4}{l}{ Table 2. Frequency (percent) of [CA15-3] $\geq 30$ unit $/ \mathrm{mL}($ abnormal) in the 2 groups } \\
\hline Group & Abnormal [CA15-3] $\geq 30$ & Normal [CA15-3] $<30$ & $\mathrm{p}^{*}$ \\
\hline (N) & $0(0.0)$ & $22(100.0)$ & 0.167 \\
(Y) & $6(12.5)$ & $42(87.5)$ & \\
All patients & $6(8.6)$ & $64(91.4)$ & \\
* Based on Fisher's exact t test & & &
\end{tabular}

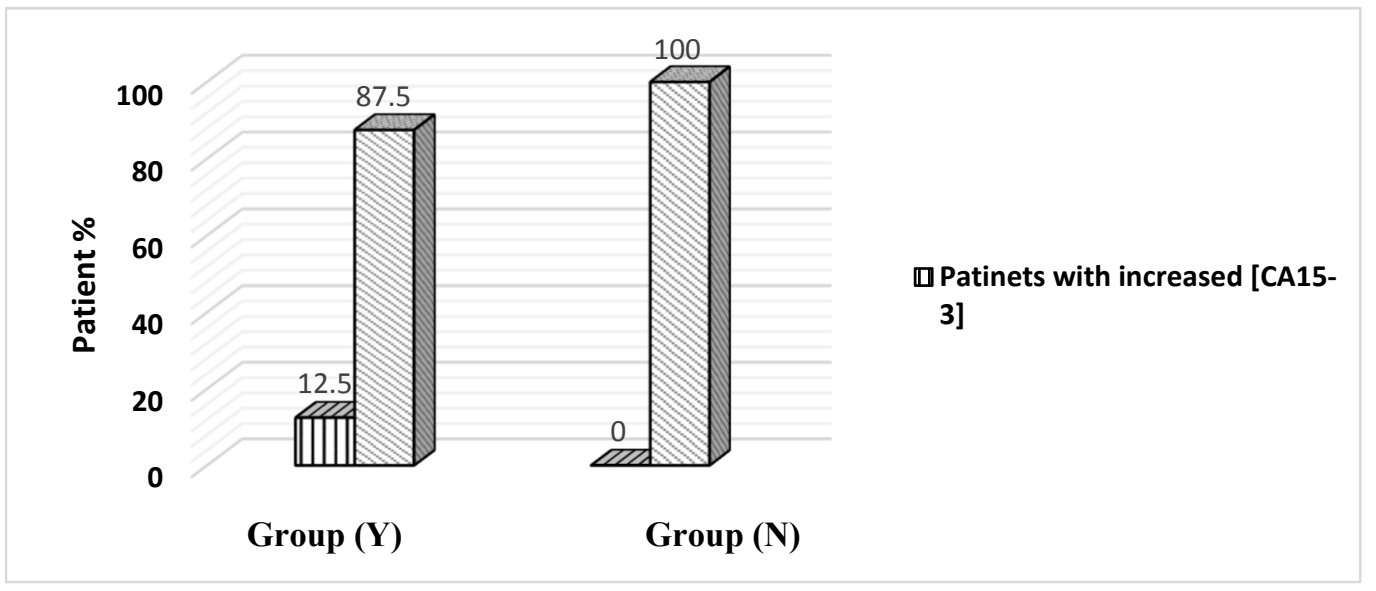

Diagram 1. Percentage of increased (abnormal) and normal levels of CA15-3 in patients with/without bony metastasis based on CA15-3 $\geq 30$

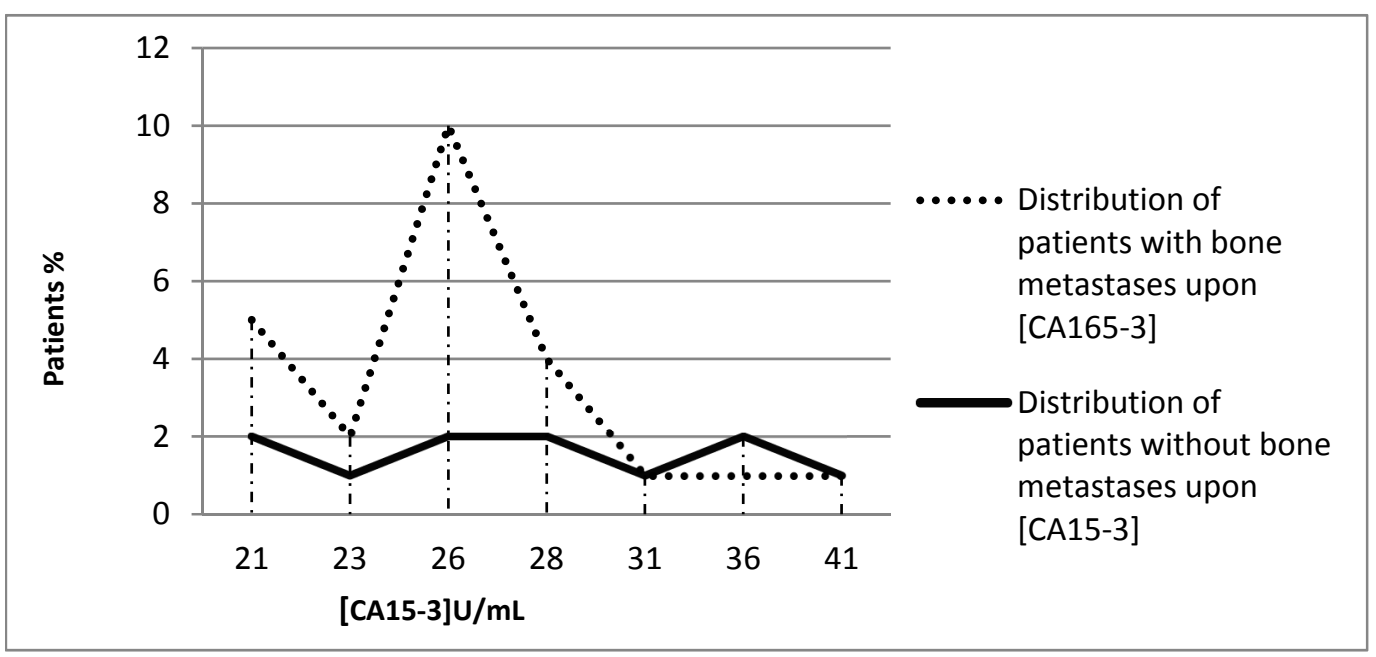

Graph 1. Distribution of patients with/without bony metastases based on serum level of CA15-3 (U/mL) 


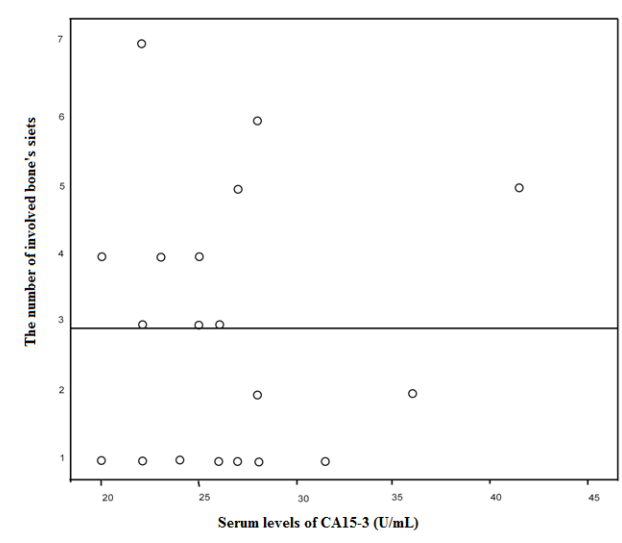

Graph 2. Asscociation between CA15-3 and spreading rate of bone metastases $(\mathrm{r}=-0.07, \mathrm{p}=0.851)$

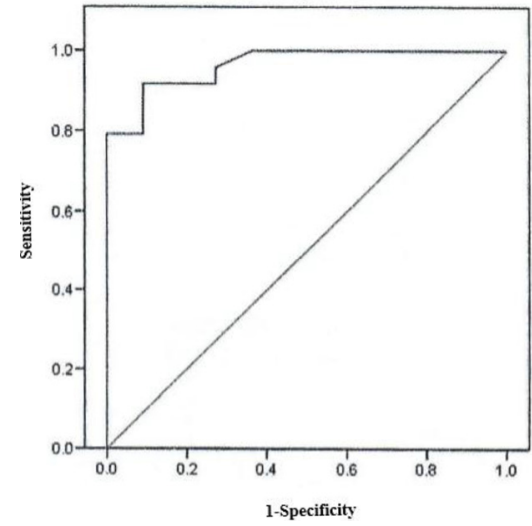

Graph 3. Plotting ROC curve of [CA15-3] to evaluate bone metastases

Table 3. Sensitivity \& specificity for different cutoff points in the diagnosis of breast cancer bone metastases

\begin{tabular}{cccccc}
\hline Specificity & Sensitivity & $<(\mathrm{U} / \mathrm{mL}) \mathrm{CA} 15-3$ & Specificity & Sensitivity & $<(\mathrm{U} / \mathrm{mL}) \mathrm{CA} 15-3$ \\
\hline $0.00 \%$ & $100 \%$ & 15.50 & $100 \%$ & $79.20 \%$ & 22.25 \\
$9.10 \%$ & $100 \%$ & 16.70 & $100 \%$ & $79.20 \%$ & 22.75 \\
$18.20 \%$ & $100 \%$ & 19.95 & $100 \%$ & $75.00 \%$ & 23.50 \\
$27.30 \%$ & $100 \%$ & 17.50 & $100 \%$ & $70.80 \%$ & 25.50 \\
$36.40 \%$ & $100 \%$ & 18.25 & $100 \%$ & $54.20 \%$ & 26.50 \\
$45.50 \%$ & $100 \%$ & 18.75 & $100 \%$ & $41.70 \%$ & 27.50 \\
$36.60 \%$ & $100 \%$ & 19.50 & $100 \%$ & $29.20 \%$ & 33.75 \\
$72.80 \%$ & $95.80 \%$ & 20.05 & $100 \%$ & $12.50 \%$ & 33.65 \\
$72.80 \%$ & $91.70 \%$ & 20.55 & $100 \%$ & $8.30 \%$ & 42.30 \\
$81.80 \%$ & $91.70 \%$ & 21.30 & $100 \%$ & $4.20 \%$ & $0.00 \%$ \\
$91.90 \%$ & $91.70 \%$ & 21.76 & $100 \%$ & & \\
\hline
\end{tabular}

Table 4. Descriptive statistics for CA15-3 of patients in the 2 groups based on new cutoff points

\begin{tabular}{lccc}
\hline Group & Mean (SD) & Min-Max & $\mathrm{p}^{*}$ \\
\hline (N-new) & $18.94(2.01)$ & $16.5-22.5$ & $<0.001$ \\
(Y-new) & $27.05(4.33)$ & $20-41$ & \\
All patients & $23.01(3.17)$ & $16.5-22.5$ & \\
\hline * Based on independent sample t-test & & &
\end{tabular}

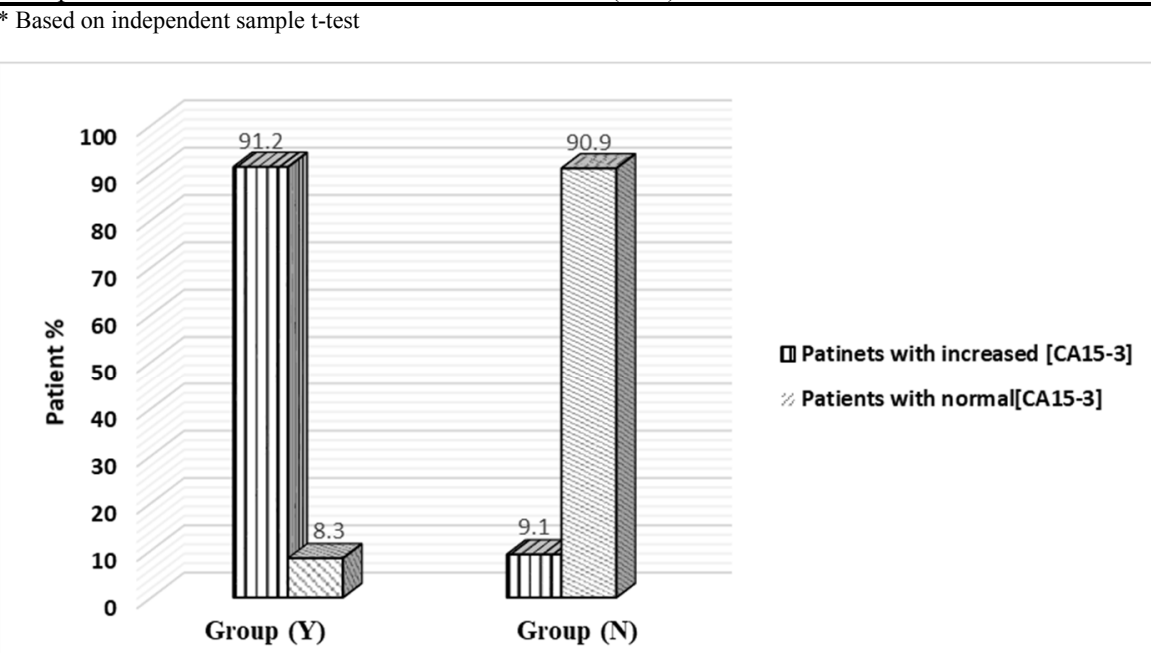

Diagram 2. Percentage of increased and normal levels of CA15-3 in patients with/without bony metastasis based on new cutoff points

\section{Discussion}

In this study, the relationship between CA15-3 and results of bone scintigraphy was investigated in the enrolled patients (14). The bone scan was assumed as a gold standard. However, in suspicious bone lesions, MRI is routinely recommended (15). Patients with bone metastases had elevated serum tumor markers (27.05) compared to patients without bone metastases who had a serum level of 18.94
Geng et al reported that elevated serum level of CA15-3 was associated with bone metastases $(\mathrm{p}=0.017)(16)$. Also, they found that although elevated [CA15-3] resulted from skeletal metastases, it was not correlated with bone scan findings (17). Zhen-Yu He et al investigated whether there was a correlation between CA15-3 and the risk of site-specific metastases in metastatic breast cancer patients. They reported that increased CA15-3 is a principle predictive 
factor for bone metastases (OR 1.688; 95\% CI, $0.992-$ 2.874; $\mathrm{p}=0.054$ ) (18). Carsten Nieder et al studied different serum levels of CA15-3 to assay their prognostic impact in patients with breast cancer. They found that among all their participants (patients with breast cancer), only $16 \%$ had normal level of CA15-3 and abnormal levels caused sporadic metastases, especially bone metastases (19). Biao Geng et al pointed out that CA15-3 is correlated with expansion of metastasis. Also, CA15-3 was more elevated in patients with multiple metastatic site than in patients with a single metastasis $(p=0.001)(20)$. Contrary to Reference 17 , Hoor Fatima et al have shown that not only is serum concentration of tumor marker dependent on bone metastases but is also consistent with bone scan results (In fact, the higher the serum concentration, the greater the number of metastases; multiple metastases were also evident in bone scan) (21). In several studies, different increased amounts of CA15-3 were reported in patients with bony metastases (22-25). Ali HQ et al had assayed CA15-3 with early diagnosis and treatment in patients with breast cancer. They placed great importance on the significant association of CA15-3 and size of primary tumor $(p<0.05)(26)$. Another study investigated whether the presurgical CA15-3 could predict the short-term disease-free survival (DFS) in patients with breast cancer. They reported that patients with [CA15-3] $(\leq 30 \mathrm{U} / \mathrm{mL})$ had better DFS than patients with CA15-3 ( $\geq 30 \mathrm{U} / \mathrm{mL})$. Moreover, they demonstrated that CA15-3 was positively correlated with the initial tumor size (27). Incoronato et al studied the association between CA15-3 and PET/CT (hybrid positron emission tomography and computed tomography) findings. They reported that increased CA15-3 could be positively associated with $\mathrm{PET} / \mathrm{CT}$ findings in patients with breast cancer. They also suggested that patients who are in the next phase of treatment with elevated serum marker tumor levels and negative PET/CT results should be seriously considered. Because high serum levels of the tumor marker indicate malignant metabolically active lesions; and as a result, there is a chance of cancer recurrence (28). The correlation between bone scan and CA15-3 found by Younsi et al suggested that in patients with related bone metastases but normal CA15-3, the CA15-3 will increase to reach abnormal levels (29). During the present study, [CA15-3] $(\geq 30)$ unit $/ \mathrm{mL}$ did not result in meaningful differences between $(\mathrm{N})$ and $(\mathrm{Y})$ groups. Thus, a new cross section was introduced at the $[\mathrm{CA} 15-3] \geq 21.76 \mathrm{unit} / \mathrm{mL}$ and led to meaningful and significant differences between $(\mathrm{N})$ and $(\mathrm{Y})$, which was associated with $91.70 \%$ and $91.90 \%$ sensitivity and specificity, respectively.

\section{Conclusion}

In this study, the amount of CA15-3 was significantly more in group $\mathrm{Y}$ than in group N. Moreover, there was no meaningful statistic correlation between CA15-3 and bone spreading rate. Also, there was not any meaningful difference between the 2 groups with regards to CA15-3 (>30 $\mathrm{U} / \mathrm{mL}$ ). By introducing a new cross section at CA15-3 $(>21.76 \mathrm{U} / \mathrm{mL})$, significant differences were developed, suggesting that CA15-3 could be useful in early prognosis of bone metastases if an effective cross section is considered, specifically in advanced. Furthermore, based on ascending statistics of breast cancer, it seems that the decreased threshold of CA15-3 should be considered instead of $\geq 30$. For instance, CA15-3 ( $\geq 21.76 \mathrm{U} / \mathrm{mL})$ seems to be appropriate for the patients in this study despite CA15-3 $(\geq 30 \mathrm{U} / \mathrm{mL})$. In general, in this study and similar surveys, it has been suggested that CA15-3 is a contributory parameter in estimating occurrence of metastases. By an appropriate cutoff point, CA15-3 could be a warning sign for bone metastases in involved patients during the treatment process. In this study, it was found that patients with CA15$3(\geq 21.76 \mathrm{U} / \mathrm{mL})$ were most likely to be involved with bone metastases.

\section{Acknowledgments}

The authors thank Medical Radiation Sciences Research Team and Tabriz University of Medical Sciences for their support.

\section{Conflict of Interests}

The authors declare that they have no competing interests.

\section{References}

1. Howlader N, Noone AM, Krapcho M. (eds). SEER Cancer Statistics Review, 1975-2009 (Vintage 2009 Populations). National Cancer Institute. Bethesda, MD, 2012.

2. Fakhari A, Jalilian AR, Yousefnia H, Johari-Daha F, Mazidi M, Khalaj A. Development of $166 \mathrm{Ho}$-pamidronate for bone pain palliation therapy. J Radioanal Nuucl Chem. 2014 Sep;303(1):743-750.

3. American Cancer Society. Breast Cancer Facts \&Figures 2017-2018. Atlanta: American Cancer Society, Inc. 2017.

4. Munazzah Rahmani M, Sulma Mohammed S. Breast cancer metastasis and the lymphatic system. Oncol Lett. 2015 Sep;10(3):1233-1239.

5. Kirsten Steinauer K, Huang DJ, Eppenberger-Castori S, Esther Amann E, Güth U. Bone metastases in breast cancer: Frequency, metastatic pattern and non-systemic locoregional therapy. J Bone Oncol. 2014 May;3(2):54-60.

6. Gillian Bedard G, Edward Chow E. The failures and challenges of bone metastases research in radiation oncology. J Bone Oncol. 2013 Jun;2(2):84-88.

7. Pulido C, Vendrell I, Ferreira AR, Casimiro S, Mansinho A, Alho I, Costa L. Bone metastasis risk factors in breast cancer. Ecancermedicalscience. 2017;11:715

8. Lu X, Kang Y. Epidermal growth factor signalling and bone metastasis. Br J Cancer. 2010 Feb 2;102(3):457-461.

9. Padera TP, Meijer EF, Munn LL. The Lymphatic System in Disease Processes and Cancer Progression. Annu Rev Biomed Eng. 2016 Jul $11 ; 18: 125-58$

10. Giulio Maccauro G, Spinelli MS, Mauro S, Perisano C, Graci C, Rosa MA. Physiopathology of Spine Metastasis. Int J Surg Oncol. 2011;2011:107969.

11. Peepre K. ${ }^{99 \mathrm{~m}} \mathrm{Tc}-\mathrm{MDP}$ Bone Scan in the Detection of Bone Metastases in Breast cancer. IOSR-JDMS. 2014 Jan;13(1):82-86.

12. Bae KU, Kim SH, Hyun Oo J, Sun Sohn H, Chung SK. Comparison between 3-phase bone scan and MRI in diagnosis of osteomyelitis. J Nucl Med. 2010 May;2:1635.

13. Echeverria L, Drudge-Coates L, Wilkins C, H. Muir G. Bone Scan Is of Doubtful Value as a First Staging Test in the Primary Presentation of Prostate Cancer. ISRN Oncol. 2012;2012:585017.

14. Fejzić H, Mujagić S, Azabagić S, Burina M. Tumor marker CA 15-3 in breast cancer patients. Acta Med Acad. 2015;44(1):39-46.

15. Guidelines for basic MRI of suspected bone and soft tissue tumours, The Scandinavian Sarcoma Group 2012.

16. Geng B, Liang MM, Xiao YE, Zhao WY. Association of CA 15-3 and CEA with clinicopathological parameters in patients with metastatic breast cancer. Mol Clin Oncol. 2015 Jan;3(1):232-236. 
17. Ghadge M, Naik P, Tiwari B, Hegde R,. Matale T. A Comparative Study of Bone Scan Findings and Serum Levels of Tumor Marker CA15-3 in Patients with Breast Carcinoma. Indian J Clin Biochem. 2012 Jan; 27(1):97-99.

18. He ZY, Xun Li X, Chen QS, Sun JY, Li FY, San-Gang Wu SG, Lin HX. Elevated serum carcinoembryonic antigen and CA15-3 levels and the risk of site-specific metastases in metastatic breast cancer. Transl Cancer Res. 2016 Oct;5(5):529-537.

19. Niedera C, Dalhauga A, Hauklanda E, Mannsakera B, Adam Pawinskia A. Prognostic Impact of the Tumor Marker CA 15-3 in PatientsWith Breast Cancer and Bone Metastases Treated with Palliative Radiotherapy. J Clin Med Res. 2017;9(3):183-187.

20. Geng BENG, Liang MM, Ye XB, Zhao WY. Association of CA 153 and CEA with clinicopathological parameters in patients with metastatic breast cancer. Mol Clin Oncol. 2015 Jan;3(1):232-236.

21. Fatima H, Maqbool A, Siddiqui M, Haider G, Sohail H, Saleem O, Ahmed A. Significance of Tumor Marker CA15-3 in Metastatic Breast Cancer. J Cancer Tumor Int. 2016;4(3):1-12.

22. Yerushalmi R, Tyldesley S, Kennecke H, Speers C, Woods R, Knight B, Gelmon KA. Tumor markers in metastatic breast cancer subtypes: frequency of elevation and correlation with outcome. Ann Oncol. 2012 May;23:338-345.

23. Kabel A. Tumor markers of breast cancer: New prospectives. J Oncol Sci. 2017 Apr;3(1):5-11.

24. Duffy MJ, Evoy D, McDermott EW. CA 15-3: uses and limitation as a biomarker for breast cancer. Clin Chim Acta. 2010 Dec 14;411(2324):1869-74.

25. Fu Y, Hui Li H. Assessing Clinical Significance of Serum CA15-3 and Carcinoembryonic Antigen (CEA) Levels in Breast Cancer Patients: A Meta-Analysis. Med Sci Monit. 2016;22:3154-3162.

26. Ali HQ, Mahdi NK, Al-Jowher MH. The value of CA15-3 in diagnosis, prognosis and treatment response in women with breast cancer. $\mathrm{J}$ Pak Med Assoc. 2013 Sep;63(9):1138-41.

27. Mudduwa LK, Wijayaratne GB, Peiris HH, Gunasekera SN, Abeysiriwardhana D, Liyanage N. Elevated pre-surgical CA15-3: does it predict the short-term disease-free survival of breast cancer patients without distant metastasis? Int J Womens Health. 2018;10:329-335.

28. Incoronato M, Peppino Mirabelli P, Catalano O, Aiello M, Parente C, Soricelli A, Nikolai E. CA15-3 is a useful serum tumor marker for diagnostic integration of hybrid positron emission tomography with integrated computed tomography during follow-up of breast cancer patients. BMC Cancer. 2014 May; 14:356.

29. Montravers F, Younsi N, Rousseau C, Philippe C, Seddiki M, Uzan $\mathrm{S}$, et al. Comparison of bone scanning and CA 15-3 serum concentration in the follow-up of breast cancer. Anticancer Res. 1997 MayJun;17(3B):1683-6. 